\title{
The association of lipid metabolism relative gene polymorphisms and ischemic stroke in Han and Uighur population of Xinjiang
}

\author{
Yun-hua Yue ${ }^{*}$, Ling-yun Liu', Liang Hu¹, You-mei Li', Jie-ping Mao², Xiao-ying Yang ${ }^{2}$ and Na-mu Dila²
}

\begin{abstract}
Background: The present study is aimed to evaluate difference of lipid metabolism related gene single nucleotide polymorphisms (SNPs) with ischemic stroke (IS) in Han and Uighur population of Xinjiang, China.

Methods: Four hundred eight patients with ischemic stroke and 347 unrelated healthy individuals of age and sex matched were genotyped for Apolipoprotein A5 (ApoA5), lipoprotein lipase (LPL), Cholesteryl ester transfer protein (CETP) and low-density lipoprotein receptor (LDL-R) genes. Their mutation difference was analyzed by SNaP shot techniques. GeneMapper4.1 SPSS20.0 software was used for data management and analysis. Using a single locus analysis, the distribution difference of genotype loci in ischemic stroke cases and controls were detected to assess the genetic risk factors of ischemic stroke.

Results: Significance differences of genotype distribution in ischemic stroke cases and controls were observed in LDLR rs688 in Han and Uighur population in recessive model from analysis of single gene locus. It also was found that dramatic difference of triglyceride (TG) of LPL rs328 and systolic blood pressure in CETP rs708277 of total population. In binary logistic regression analysis of total studied population, ischemic stroke was observed significantly associated with LDLR rs688 both addictive model (TT/CC, adjusted OR $=1.47,95 \%$ $\mathrm{Cl}=1.04-2.07)$ and recessive model (TT/CT $+C C$, adjusted Odds ratio $(\mathrm{OR})=2.66,95 \%$ Confidence Interval $(\mathrm{Cl})=1.37-5.14)$. In Han population, ischemic stroke was observed significantly associated with rs688 both in addictive model (TT/CC, adjusted $\mathrm{OR}=3.27,95 \% \mathrm{Cl}=1.06-10.05)$. In Uighur population, no significant association was found between gene polymorphisms and the risk of ischemic stroke. Combined analysis of multiple gene and loci, interaction effects of LDLR rs688 C/T, ApoA5 rs662799 A/G and CETP rs708272 C/T denoted a significant influence on IS susceptibility.
\end{abstract}

Conclusion: Single nucleotide polymorphisms of lipid metabolism relative gene were significantly associated with the morbidity of ischemic stroke in Han population. The interaction effects of rs688 C/T with ApoA5 rs662799 A/G and CETP rs708272 C/T promoted the occurrence of IS.

Keywords: Apolipoprotein, Low density lipoprotein receptor, Ischemic stroke, Single nucleotide polymorphism

\footnotetext{
*Correspondence: 447879206@qq.com

${ }^{1}$ Department of Neurology, Yangpu Hospital Tongji University School of

Medicine, No. 450 Tengyue Road, Shanghai 200090, China

Full list of author information is available at the end of the article
} 


\section{Background}

Stroke is one of the leading causes of death over the all world and cause major health problem [1]. However, it is the first cause of morality in China [2]. Ischemic stroke (IS) frequently caused dysfunction of the brain and comprises $80 \%$ of cases [3]. The reasons for the patho-physiological cause of ischemic stroke are unclear. The concept was widely accepted that stroke is caused by combination of genetic and environment factors. Among genetic factors, it well known that a few specific gene variants of lipid metabolism are modifiable risk factors for the occurrence of IS [1, 4]. The extensive study indicated that atherosclerotic plaques form is the major cause of IS $[5,6]$, which the occurrence of atherosclerotic plaques are strongly associated with abnormal lipid metabolism $[7,8]$. So far, it was known that Apolipoprotein A5 (ApoA5), lipoprotein lipase (LPL), Cholesteryl ester transfer protein (CETP) and low-density lipoprotein receptor (LDL-R) gene mutations had increased the concentration of lipids [9-11].

The association of human candidate genes with IS patients may be the confounding effects of ethnic, environment factor and individual life style [12]. Xinjiang region of China lies in the north-west part of the mainland and the weather is dry and cold. There is a high altitude in this area and relative lack of oxygen. Furthermore, the Uighur population has different risk factors of ischemic stroke than Han population because of the ethnicity, genetic background and lifestyle. The most population in Xinjiang had more caloric food and alcoholic intake $[13,14]$. Hu et al. reported that the risk of dyslipidemia in CETP rs708272 CC of Uighur residents was much higher that rs708272 CT or TT genotype [15]. Quan et al. found that the patients with impaired fasting glucose (IFG) in Uighur population had more risk for dyslipidemia than Han population with IFG [16]. Li et al. showed that the level of hypercholesterolemia in Kazakh population of Xinjiang was significant higher than it in Uygur and Han [17]. These data indicated that different genetic background had more effect on their serum lipids level. Therefore, we determined to investigate ApoA5, LPL, CETP and LDLR gene single nucleotide polymorphisms (SNPs) in Han and Uighur population of Xinjiang region because of their different ethnicity, genetic, environment factors background and life style. These results will provided a unique link between the relationships the lipid metabolism related gene SNP with the occurrence of IS.

\section{Methods}

\section{Study subjects}

Patients with ischemic stroke of 250 Han and 158 Uighur population and were enrolled from Department of Neurology of the Youyi Hospital of Wulumuqi from July 2010 to July 2012. Three hundred forty-seven age and sex matched unrelated healthy individuals also were included in this study as a control The inclusion and exclusion criteria for ischemic stroke were determined as our previous described [18]. The hypertension and Diabetes mellitus (DM) diagnosis criteria were described as our and the other lab $[18,19]$. Briefly, blood pressure (BP) was measured at routine method. The second BP with the fifth-phase diastolic pressure was used for analysis. Diabetes mellitus (DM) was classified as fasting plasma glucose (FPG) $\geq 7.0 \mathrm{mmol} / \mathrm{L}$ and/or $2 \mathrm{~h}$ plasma glucose (PG) $\geq 11.1 \mathrm{mmol} / \mathrm{L}$ or already diagnosed as diabetes patients. To assess the relationship of hypertension and DM with dislipidemia, the lipid level in IS patients with hypertension and DM was evaluated. This study protocol was approved by the Youyi hospital ethics committee and all participants were given signed informed consent.

\section{DNA extraction}

$5 \mathrm{ml}$ of peripheral whole blood was collected in an EDTA coated vacutainerand blood samples were stored at $4{ }^{\circ} \mathrm{C}$ before DNA extraction. The genomic DNA was isolated using Qiagen DNA mini isolation kit. All procedure was performed according to kit description. DNA concentration and purity were determined by Nano Drop 2000 machine (Thermo Scientific, USA).

\section{Selection of SNP candidate genes}

To identify the most likely relative lipoprotein SNP candidate genes, we accessed to http://www.ncbi.nlm.nih.gov/ SNP database and selected APOA5, LPL, CETP and LDLR genes asour candidate genes association with acute IS.

Genotyping of the ApoA5, LPL, CETP and LDLR gene SNPs DNA sample were analyzed by SNaPshot SNP typing machine (SnaPshot multiplex, ABI, USA). Detail PCR and single-base extension primer sequences were recorded as our previous study [18].

\section{Statistical analysis}

The statistical analysis was performed using SPSS 20.0(IBM, USA). Clinical parameter such as serum TC, TGL, HDL-C, LDL-C, ApoA1, ApoB, Lpa glucose, and serumwere measured with automatic machine in IS patients and controls. The allelic frequencies were calculated by Hardy-weinberg equipment method. Multivariate logistic regression analyses were performed for genotype, allele frequencies and lipid profile factor associated with ischemic stroke. Through counting DNA sequencing data, the genotype and allele frequencies can be estimated. The distinction between studied groups were analyzed by Pearson's $\mathrm{X}^{2}$ test. Then, logistic regression analysis was measured the strength. 
Table 1 Candidate genes and SNP information

\begin{tabular}{|c|c|c|c|}
\hline Gene & $\begin{array}{l}\text { IS group } \\
(n=408)\end{array}$ & $\begin{array}{l}\text { Control group } \\
(n=347)\end{array}$ & $P$ \\
\hline Age (year-old) & $61.9 \pm 11.8$ & $61.8 \pm 11.7$ & 0.916 \\
\hline Sex (Male/Female, $N$ ) & $242 / 166$ & $201 / 146$ & 0.943 \\
\hline BMI (kg/m2) & $24.2 \pm 3.3$ & $23.9 \pm 4.1$ & 0.542 \\
\hline Hypertension (N, \%) & $281(68.9)$ & 129(37.2) & $<0.001$ \\
\hline $\mathrm{DM}(N, \%)$ & 129 (31.6) & $46(13.3)$ & $<0.001$ \\
\hline $\mathrm{TC}(\mathrm{mmol} / \mathrm{L})$ & $4.85 \pm 1.08$ & $4.47 \pm 1.01$ & $<0.001$ \\
\hline $\mathrm{TG}(\mathrm{mmol} / \mathrm{L})$ & $1.71 \pm 0.65$ & $1.51 \pm 0.66$ & $<0.001$ \\
\hline LDL-C (mmol/L) & $3.28 \pm 0.61$ & $2.46 \pm 0.63$ & $<0.001$ \\
\hline $\mathrm{HDL}-\mathrm{C}(\mathrm{mmol} / \mathrm{L})$ & $1.06 \pm 0.25$ & $1.27 \pm 0.26$ & $<0.001$ \\
\hline ApoA1 (g/L) & $0.83 \pm 0.22$ & $1.03 \pm 0.31$ & $<0.001$ \\
\hline ApoB (g/L) & $0.81 \pm 0.22$ & $0.95 \pm 0.35$ & $<0.001$ \\
\hline Lpa (mg/L) & $173.57 \pm 53.17$ & $123.81 \pm 62.43$ & $<0.001$ \\
\hline
\end{tabular}

SNP single nucleotide polymorphism, BMI Body Mass Index, IS ischemic stroke, DM Diabetes mellitus, TC Total Cholesterol, TG Triglycerides, LDL-C low Density Lipoprotein-C, HDL-C High Density Lipoprotein-C, ApoA1 Apolipoprotein-A1, $A p o B$ Apolipoprotein B, Lpa lipoprotein a

\section{Results}

Clinical character of subjects

The basic clinical characteristics of the 408 IS patients and 347 control were shown in Table 1. There were no significant difference in age, sex and body mass index (BMI), However, it was greatly differences in hypertension, diabetes mellitus (DM); Total Cholesterol (TC); Triglycerides (TG); low Density Lipoprotein-C (LDL-C); High Density Lipoprotein-C (HDL-C); ApolipoproteinA1 (ApoA1); Apolipoprotein B (ApoB); lipoprotein a (Lpa) $(P<0.001)$. Therefore, these clinical parameters provide an evidence that IS patients often have abnormal serum lipoprotein level. It also is closed association with hypertension and DM history.

\section{Lipidsmetabolism relative genes SNP information}

After we accessed to http://www.ncbi.nlm.nih.gov/SNP database a, it was found that possible APOA5, LPL, CETP and LDLR genes candidate SNP site were shown in Table 2.

Table 2 Candidate Genes and SNP information

\begin{tabular}{lllllll}
\hline Gene & Locus & Function & Sites & HF & LF & Reference \\
\hline APOA5 & rs662799 & 5'-flanking & $116,663,707$ & A & G & $0.267(\mathrm{HCB})$ \\
LPL & rs320 & Intron & $19,819,077$ & T & G & NA(HCB) \\
& rs328 & Ser474Ter & $19,819,724$ & $\mathrm{C}$ & $\mathrm{G}$ & $0.089(\mathrm{HCB})$ \\
CETP & rs708277 & Intron & $56,996,288$ & $\mathrm{C}$ & $\mathrm{T}$ & $\mathrm{NA}(\mathrm{HCB})$ \\
LDLR & rs688 & Asn591Asn & $11,227,602$ & $\mathrm{C}$ & $\mathrm{T}$ & $0.174(\mathrm{HCB})$
\end{tabular}

SNP single nucleotide polymorphism, ApoA5 Apolipoprotein-A5, LPL lipoprotein lipase, CETP Cholesteryl ester transfer protein, $L D L R$ Low density lipoprotein receptor, $H F$ high frequency, $L F$ low frequency, NA no answer, $H C B$ Han, Chinese and Beijing
Table 3 Hardy-Weinberg equilibrium test of Overall sample case group

\begin{tabular}{lllllll}
\hline SNP & A1 & A2 & AN & EN & X2 & $P$ \\
\hline Rs662799 & G & A & $30 / 153 / 225$ & $28 / 157 / 223$ & 0.263 & 0.877 \\
Rs320 & G & T & $12 / 121 / 275$ & $13 / 119 / 276$ & 0.114 & 0.945 \\
Rs328 & G & C & $1 / 58 / 349$ & $2 / 56 / 350$ & 0.574 & 0.768 \\
Rs708272 & A & G & $81 / 196 / 131$ & $79 / 201 / 129$ & 0.204 & 0.903 \\
Rs688 & T & C & $40 / 130 / 238$ & $27 / 156 / 225$ & 11.344 & 0.003 \\
\hline
\end{tabular}

SNP single nucleotide polymorphism, AN Actual number, EN

Expectable number

These mutations were verified by PCR and DNA product sequencing. These data confirmed that these candidate genes were indeed mutated in IS patients.

The distribution difference of ApoA5 rs662799, LPL rs320, rs328, CETP rs708277, LDLR rs688 mutation with IS in Han and Uighur population by Hardy-Weinberg equilibrium test

We compared the distribution difference of APOA5 rs662799, LPL rs320, LPL rs328, CETP rs708277 and LDLR rs688 gene loci in IS and control Han and Uighur population of Xinjiang. Then we calculated the difference in overall case and control group by HardyWeinberg equilibrium test. Data were shown in Tables 3 and 4. The frequencies of LDLR rs688 mutation were dramatic increased in IS patients than the controls $(P=0.003)$. This result strongly supports the association LDLR mutation with IS. However, there was no difference that the frequencies of ApoA5 rs662799, LPL rs320, LPL rs328, CETP rs708272 in Hardy-Weinberg equilibrium test.

The distribution difference of ApoA5 rs662799, LPL rs320, rs328, CETP rs708277, LDLR rs688 mutation with IS and control according to their dominant, recessive and codominant genetic style by pearson $\mathrm{X}^{2}$ and CHISP test The next, we compared the difference of ApoA5, LPL, CETP and LDLR SNP mutation between Han and Uighur IS patients and control by pearson $\mathrm{X}^{2}$ test. The result were shown in Tables 5 and 6. By

Table 4 Hardy-Weinberg equilibrium test of Overall sample CONTROL group

\begin{tabular}{lllllll}
\hline SNP & A1 & A2 & AN & EN & X2 & $P$ \\
\hline Rs662799 & G & A & 25/110/212 & $18 / 123 / 205$ & 4.320 & 0.115 \\
Rs320 & G & T & $13 / 99 / 235$ & $11 / 102 / 233$ & 0.465 & 0.793 \\
Rs328 & G & C & $1 / 58 / 349$ & $2 / 56 / 350$ & 0.574 & 0.768 \\
Rs708272 & A & G & $82 / 160 / 105$ & $76 / 173 / 99$ & 1.817 & 0.403 \\
Rs688 & T & C & $14 / 129 / 204$ & $18 / 121 / 208$ & 1.495 & 0.474
\end{tabular}

$S N P$ single nucleotide polymorphism, AN Actual number, $E N$ Expectable number 
Table 5 The distribution of different genotype of recessive between two Uighur groups

\begin{tabular}{llllll}
\hline SNP & Recessive & Case & Control & X2 & $P$ \\
\hline Rs662799 & GG:(GA + AA) & $30 / 378(7.4 / 92.6)$ & $25 / 322(7.2 / 92.8)$ & 0.006 & 0.938 \\
Rs320 & GG:(GT + TT) & $12 / 396(2.9 / 97.1)$ & $13 / 334(3.7 / 96.3)$ & 0.380 & NA \\
Rs328 & GG:(GC + CC) & $1 / 407(0.2 / 99.8)$ & $3 / 344(0.9 / 99.1)$ & NA \\
Rs708272 & AA:(GA + GG) & $81 / 327(19.9 / 80.1)$ & $82 / 265(23.6 / 76.4)$ & 1.581 & 0.209 \\
Rs688 & TT:(CT + CC) & $40 / 368(9.8 / 90.2)$ & $14 / 333(4.0 / 90.6)$ & 9.399 & 0.002 \\
\hline
\end{tabular}

SNP single nucleotide polymorphism, N/A no answer

contrast, either Uighur (Table 5) or Han population (data not shown) was highly significant when compared to respective controls in recessive genetic model. However, associations were not significant in dominant genetic model. Interest, this result also is consistent by CHISP test (Tables 6 and 7). Further, no significant association was found in dominant and codominant genetic model in stroke cases (data not shown).

Association of ApoA5 rs662799, LPL rs320, rs328, CETP rs708277, LDLR rs688 mutation with IS in Han and Uighur population by binary logistic regression analysis

We further compared the difference of IS patients and control by binary logistic regression analysis. It was observed significantly associated with rs688 both addictive model (TT/CC, adjusted OR $=1.47,95 \% \mathrm{CI}=1.04-2.07, P<0.01$ ) and recessive model $(\mathrm{TT} / \mathrm{CT}+\mathrm{CC}$, adjusted $\mathrm{OR}=2.66$, 95\% CI $=1.37-5.14, p=0.004$ ) (Tables 8 and 9). In Han population, ischemic stroke was observed significantly associated with rs688 both in addictive model (TT/CC, adjusted $\mathrm{OR}=3.27,95 \% \mathrm{CI}=1.06-10.05, P<0.05)$. In Uighur population, no significant association was found between gene polymorphisms and the risk of ischemic stroke (data not shown). Combined analysis of multiple gene and loci, interaction effects of LDLR rs688 C/T, ApoA5 rs662799 A/ $\mathrm{G}$ and CETP rs708272 C/T denoted a significant influence on IS susceptibility $(p<0.05)$.

\section{Association of LPL rs328 and CETP rs708277 with serum} lipid protein levels and clinical profile in total population To explore the association of lipid metabolism gene SNPs with serum lipid protein levels and clinical profile, we detected major serum lipid levels, glucose, height, weight, BMI and blood Pressure with LPL rs328 and CETP.rs70877 in total population. Data were shown in Tables 10 and 11 . We found that there are significant lower TG in rs328 GG than in rs328 CC and GC population (Table 10). Low SBP also was measured in CETP.rs70877 GA and AA (Table 11).

These results indicated that different lipid protein metabolism relative gene SNPs is associated with special clinical profile.

\section{Discussion}

The risk factors of stroke were extensively studied $[10,20,21]$. Recent data revealed that a few protein genetic polymorphisms were significantly association with the risk for stroke [22-24]. Here, we investigated that ApoA5, LPL, CETP and LDLR gene polymorphisms in IS patients from Xinjiang region. The results provided linkage of different genetic background, life style and the occurrence of ischemic stroke.

Our study showed the presence of ApoA5 rs662799, LPL rs320, LPL rs328(Ser474 Ter), CETP rs708277 and LDLR rs688 in IS patients from Xinjiang region. Surprisingly, it was observed that rs688 genetic polymorphism had significantly more difference in IS patients than in control in recessive model analysis. This phenomenon also was seen by binary logistic regression analysis of total studied population. IS patients was observed significantly associated with rs688 both addictive model $(\mathrm{TT} / \mathrm{CC}$, adjusted $\mathrm{OR}=1.47,95 \% \mathrm{CI}=1.04-2.07$, $P<0.01)$ and recessive model (TT/CT $+\mathrm{CC}$, adjusted $\mathrm{OR}=2.66,95 \% \mathrm{CI}=1.37-5.14, p<0.01)$. In Han population, ischemic stroke was observed significantly associated

Table 6 The distribution of different genotype of recessive between two Han groups

\begin{tabular}{|c|c|c|c|c|c|}
\hline$\overline{S N P}$ & Recessive & Case & Control & CHISP & $P$ \\
\hline Rs662799 & $G G:(G A+A A)$ & $21 / 229(8.4 / 91.6)$ & $19 / 179(9.6 / 90.4)$ & 0.194 & 0.659 \\
\hline Rs320 & $G G:(G T+T T)$ & $10 / 240(4.0 / 96.0)$ & 8/190(4.0/96.0) & 0.000 & 0.983 \\
\hline Rs328 & GG:(GC + CC) & 1/249(0.4/99.6) & $3 / 195(1.5 / 98.5)$ & NA & NA \\
\hline Rs708272 & $A A:(G A+G G)$ & 49/201 (19.6/80.4) & $49 / 149(24.7 / 75.3)$ & 1.713 & 0.191 \\
\hline Rs688 & $\Pi:(C T+C C)$ & $16 / 234(6.4 / 93.6)$ & 4/194(2.0/98.0) & 4.970 & 0.036 \\
\hline
\end{tabular}

SNP single nucleotide polymorphism, N/A no answer 
Table 7 The distribution of different genotype of recessive between two Uighur groups

\begin{tabular}{llllll}
\hline SNP & Recessive & Case & Control & CHISP & P \\
\hline Rs662799 & GG:(GA + AA) & $9 / 149(5.7 / 94.3)$ & $6 / 143(4.0 / 96.0)$ & 0.460 & 0.718 \\
Rs320 & GG:(GT + T) & $2 / 156(1.3 / 98.7)$ & $5 / 144(3.4 / 96.6)$ & 1.5030 .220 \\
Rs328 & GG:(GC + CC) & $0 / 158(0.0 / 100.0)$ & $0 / 149(0.0 / 100.0)$ & NA & NA \\
Rs708272 & AA:(GA + GG) & $32 / 126(20.3 / 79.7)$ & $33 / 116(22.1 / 77.9)$ & 0.165 & 0.685 \\
Rs688 & TT:(CT + CC) & $24 / 134(15.2 / 84.8)$ & $10 / 139(6.7 / 93.3)$ & 5.597 & 0.018 \\
\hline
\end{tabular}

SNP single nucleotide polymorphism, N/A no answer

with rs688 both in addictive model (TT/CC, adjusted $\mathrm{OR}=3.27,95 \% \mathrm{CI}=1.06-10.05, P<0.05)$. However, This phenomenon weren't observed in Uighur population. It was well known that a single gene may have different genetic polymorphism with different kind of disease [25-28]. The same gene in one kind of disease may have diverse SNPs owing to different race and place. It was widely reported that LDLR genetic polymorphisms are associated with many disease such as essential hypertension [28], coronary artery disease (CAD) [29] and high cholesterol [30]. These SNP site were C1773T, rs2228671, rs1122608 and so on. A similar study were reported that rs688 is associated with IS patients in Taiwanese population [24]. Gao et al. revealed that rs688 increase exon12 alternative splicing and affected LDL receptor function [27]. Zhu et al. showed that rs688 promote a high serum cholesterol by modulating LDLR exon12 splicing efficiency [30]. Therefore, we speculated that rs688 firstly increase serum cholesterol and then cause atherosclerotic plaques form.

Table 8 Additive model analysis of different genes with stroke

\begin{tabular}{lll}
\hline SNP & $P$ & OR $(95 \% \mathrm{Cl})$ \\
\hline Rs662799 & 0.205 & Ref \\
Rs662799 GA/AA & 0.139 & $1.28(0.92-1.79)$ \\
Rs662799 GG/AA & 0.112 & $1.76(0.88-3.54)$ \\
Rs320 & 0.819 & Ref \\
Rs320 GT/TT & 0.891 & $1.02(0.74-1.42)$ \\
Rs320 GG/TT & 0.551 & $0.77(0.33-1.80)$ \\
Rs328 & 0.514 & Ref \\
Rs328 GC/CC & 0.744 & $0.93(0.61-1.42)$ \\
Rs328 GG/CC & 0.264 & $0.27(0.03-2.67)$ \\
Rs708272 & 0.413 & Ref \\
Rs708272 GA/GG & 0.695 & $0.93(0.66-1.32)$ \\
Rs708272 AA/GG & 0.195 & $0.76(0.50-1.15)$ \\
Rs688 & 0.013 & Ref \\
Rs688 TC/CC & 0.611 & $0.92(0.67-1.27)$ \\
Rs688 TT/CC & 0.006 & $2.57(1.31-5.03)$ \\
\hline
\end{tabular}

SNP single nucleotide polymorphism, OR Odds ratio, $\mathrm{Cl}$ confidence interval
ApoA5 had similar phenomenon like LDLR. It was reported that ApoA5 T-1131C, T1259C, and IVS3 + G476A are associated with IS, DM and CAD [11, 25]. These SNPs result in high triglycerides. It also was widely observed that some gene SNPs are closely associated with special clinical profile in Xinjiang. Our study indicated that SNPs of lipid metabolism relative genes is associated with response of drug [18] Zhang et al. reported that there are significant difference in $\beta 3$-adrenergic receptors (ADR 33 ) gene polymorphisms rs6986132 of Han and Uighur populations in Xinjiang. They also observed the ADR $\beta 3$ rs2298423 G allele carriers increase risk for TC and LDL-C level in the Uighur populations of Xinjiang [31]. Abulizi et al. found that ApoA5 gene c553G-T polymorphism is associated with high TG levels in Han and Uighur population [32]. Our present data showed that LPL rs328 CC and GC allele people have high TG than rs328 GG allele population. People of CETP rs708277 GG allele had high SBP than it in rs708277 GA or AA allele people.

\section{Conclusion}

Our results indicated that SNPs of lipid metabolism relative gene is closely associated with different population of Xinjiang. In Han population, ischemic stroke was significantly associated with LPLR rs688 polymorphisms. However, this phenomenon didn't detect in Uighur population. We also found that different special SNPs allele have different serum lipid and blood pressure levels. These results demonstrated that we need take care of some specific SNPs people because they is easy to develop ischemic strokes.

Table 9 Recessive model analysis of different genes with stroke

\begin{tabular}{llll}
\hline SNP & & $P$ & OR $(95 \% \mathrm{Cl})$ \\
\hline Rs662799 & $\mathrm{GG} /(\mathrm{GA}+\mathrm{AA})$ & 0.745 & $1.10(0.62-1.96)$ \\
Rs320 & $\mathrm{GG} /(\mathrm{GT}+\mathrm{TT})$ & 0.537 & $0.77(0.33-1.78)$ \\
Rs328 & $\mathrm{GG}(\mathrm{GC}+\mathrm{CC})$ & 0.268 & $0.28(0.03-2.69)$ \\
Rs708272 & $\mathrm{AA} /(\mathrm{GA}+\mathrm{GG})$ & 0.204 & $0.79(0.55-1-13)$ \\
Rs688 & $\mathrm{TT} /(\mathrm{CT}+\mathrm{CC})$ & 0.004 & $2.66(1.37-5.14)$
\end{tabular}

SNP single nucleotide polymorphism, $O R$ Odds ratio, $\mathrm{Cl}$ confidence interval 
Table 10 Association comparison of rs328 genotype with stroke in study population

\begin{tabular}{|c|c|c|c|c|c|c|c|}
\hline \multirow[t]{2}{*}{ Rs328 } & \multicolumn{2}{|l|}{ CC } & \multicolumn{2}{|l|}{ GC } & \multicolumn{2}{|c|}{ GG } & \multirow[t]{2}{*}{$P$} \\
\hline & $n$ & Mean \pm SD & $n$ & Mean \pm SD & $n$ & Mean \pm SD & \\
\hline Age & 640 & $61.4 \pm 12.61$ & 111 & $64.4 \pm 9.3$ & 4 & $61.8 \pm 12.9$ & 0.052 \\
\hline Height & 637 & $1.67 \pm 0.08$ & 111 & $1.66 .1 \pm 0.08$ & 4 & $1.59 \pm 0.065$ & 0.058 \\
\hline Weight & 638 & $68.80 \pm 10.65$ & 110 & $68.28 \pm 11.39$ & 4 & $58.75 \pm 9.11$ & 0.162 \\
\hline BMl & 637 & $24.67 \pm 2.89$ & 110 & $24.78 \pm 3.00$ & 4 & $23.06 \pm 92.30$ & 0.499 \\
\hline SBP & 640 & $138.49 \pm 23.29$ & 111 & $137.05 \pm 24.52$ & 4 & $122.50 \pm 16.58$ & 0.340 \\
\hline DBP & 640 & $84.52 \pm 42.64$ & 111 & $81.50 \pm 13.84$ & 4 & $72.50 \pm 6.46$ & 0.642 \\
\hline Glucose & 640 & $6.25 \pm 3.13$ & 111 & $6.20 \pm 2.99$ & 4 & $7.48 \pm 5.45$ & 0.725 \\
\hline TG & 640 & $2.02 \pm 1.24$ & 111 & $1.70 \pm 0.99$ & 4 & $1.48 \pm 0.30$ & 0.026 \\
\hline $\mathrm{TC}$ & 640 & $4.34 \pm 1.15$ & 111 & $4.33 \pm 0.85$ & 4 & $4.70 \pm 0.61$ & 0.806 \\
\hline $\mathrm{HDL}$ & 640 & $1.19 \pm 0.66$ & 111 & $1.24 \pm 0.84$ & 4 & $1.32 \pm 0.49$ & 0.748 \\
\hline LDL & 639 & $2.66 \pm 0.86$ & 111 & $2.63 \pm 0.77$ & 4 & $2.54 \pm 0.32$ & 0.926 \\
\hline APOA1 & 640 & $1.24 \pm 0.32$ & 111 & $1.23 \pm 0.22$ & 4 & $1.07 \pm 0.23$ & 0.514 \\
\hline APOB & 640 & $0.90 \pm 0.75$ & 111 & $0.85 \pm 0.33$ & 4 & $0.99 \pm 0.18$ & 0.714 \\
\hline $\mathrm{HCY}$ & 640 & $9.98 \pm 7.29$ & 111 & $8.69 \pm 4.87$ & 4 & $5.50 \pm 2.54$ & 0.094 \\
\hline $\mathrm{TC} / \mathrm{HDL}-\mathrm{C}$ & 640 & $4.32 \pm 2.10$ & 111 & $4.08 \pm 1.34$ & 4 & $3.78 \pm 0.798$ & 0.452 \\
\hline LDL-C/HDL-C & 639 & $2.68 \pm 2.08$ & 111 & $2.51 \pm 1.04$ & 4 & $2.15 \pm 0.78$ & 0.603 \\
\hline ApoB/ApoA1 & 640 & $0.77 \pm 0.80$ & 111 & $0.71 \pm 0.34$ & 4 & $0.97 \pm 0.35$ & 0.677 \\
\hline
\end{tabular}

BMI Body Mass Index, SBP Systolic blood pressure, DBP diastolic blood pressure, TC Total Cholesterol, TG Triglycerides, LDL-C low Density Lipoprotein-C, HDL-C High Density Lipoprotein-C, ApoA1 Apolipoprotein-A1, ApoB Apolipoprotein B

Table 11 Association comparison of rs708272 genotype with stroke in study population

\begin{tabular}{|c|c|c|c|c|c|c|c|}
\hline \multirow[t]{2}{*}{ Rs708272 } & \multicolumn{2}{|l|}{ GG } & \multicolumn{2}{|l|}{ GA } & \multicolumn{2}{|l|}{ AA } & \multirow[t]{2}{*}{$P$} \\
\hline & $n$ & Mean \pm SD & $n$ & Mean \pm SD & $n$ & Mean \pm SD & \\
\hline Age & 236 & $61.0 \pm 11.67$ & 356 & $62.4 \pm 11.7$ & 163 & $62.0 \pm 11.9$ & 0.353 \\
\hline Height & 236 & $1.67 \pm 0.08$ & 354 & $1.66 .1 \pm 0.08$ & 162 & $1.67 \pm 0.07$ & 0.394 \\
\hline Weight & 235 & $68.61 \pm 10.51$ & 355 & $68.59 \pm 10.70$ & 162 & $68.94 \pm 11.33$ & 0.937 \\
\hline $\mathrm{BMI}$ & 235 & $24.49 \pm 2.273$ & 353 & $24.76 \pm 2.86$ & 163 & $24.78 \pm 3.23$ & 0.467 \\
\hline SBP & 236 & $141.33 \pm 23.96$ & 356 & $136.78 \pm 24.35$ & 163 & $136.72 \pm 20.18$ & 0.046 \\
\hline $\mathrm{DBP}$ & 236 & $88.74 \pm 67.74$ & 356 & $81.69 \pm 13.74$ & 163 & $85.26 \pm 13.96$ & 0.086 \\
\hline Glucose & 236 & $6.06 \pm 2.51$ & 356 & $6.25 \pm 2.87$ & 163 & $6.51 \pm 4.24$ & 0.371 \\
\hline TG & 236 & $2.01 \pm 1.27$ & 356 & $1.95 \pm 1.18$ & 163 & $1.95 \pm 1.20$ & 0.803 \\
\hline $\mathrm{TC}$ & 236 & $4.34 \pm 0.97$ & 356 & $4.34 \pm 1.18$ & 163 & $4.35 \pm 1.14$ & 0.997 \\
\hline $\mathrm{HDL}$ & 236 & $1.22 \pm 0.739$ & 356 & $1.19 \pm 0.65$ & 163 & $1.17 \pm 0.58$ & 0.738 \\
\hline $\mathrm{LDL}$ & 236 & $2.64 \pm 0.79$ & 356 & $2.64 \pm 0.82$ & 163 & $2.70 \pm 0.968$ & 0.718 \\
\hline APOA1 & 236 & $1.24 \pm 0.23$ & 356 & $1.22 \pm 0.23$ & 163 & $1.27 \pm 0.50$ & 0.124 \\
\hline APOB & 236 & $0.85 \pm 0.28$ & 356 & $0.92 \pm 0.81$ & 163 & $0.89 \pm 0.86$ & 0.507 \\
\hline $\mathrm{HCY}$ & 236 & $9.81 \pm 7.176$ & 356 & $9.73 \pm 6.93$ & 163 & $9.78 \pm 6.91$ & 0.991 \\
\hline $\mathrm{TC} / \mathrm{HDL}-\mathrm{C}$ & 236 & $4.21 \pm 1.60$ & 356 & $4.33 \pm 2.40$ & 163 & $4.25 \pm 1.53$ & 0.757 \\
\hline LDL-C/HDL-C & 236 & $2.59 \pm 1.12$ & 356 & $2.71 \pm 2.59$ & 163 & $2.63 \pm 1.18$ & 0.730 \\
\hline ApoB/ApoA1 & 236 & $0.71 \pm 0.28$ & 356 & $0.80 \pm 0.87$ & 163 & $0.76 \pm 0.92$ & 0.387 \\
\hline
\end{tabular}




\section{Abbreviations}

ADRß3: $\beta 3$-adrenergic receptors; ApoA5: Apo lipoprotein A5; BP: Blood pressure; CETP: Cholesteryl ester transfer protein; DM: Diabetes mellitus; FPG: Fasting plasma glucose; HT: Hypertension; IFG: Impaired fasting glucose: IS: Ischemic stroke; LDL-R: Low-density lipoprotein receptor; LPL: Lipoprotein lipase; MRI: Magnetic resonance imaging; TG: Triglyceride

\section{Acknowledgements}

None declared.

\section{Funding}

This study is supported by the project of science committee and health and birth control committee of Yangpu District of Shanghai in 2015 (No. 20150015).

\section{Availability of data and materials}

The datasets supporting the conclusions of this article are included within the article.

\section{Authors' contributions}

Y-hY contributed to the study design, L-yL and LH perform the data analysis, $\mathrm{Y}-\mathrm{mL}$ and J-pM prepare the manuscript, $\mathrm{X}-\mathrm{yY}$ and $\mathrm{N}-\mathrm{mD}$ collected the data. All authors read and approved the final manuscript.

\section{Competing interests}

All authors declare that they have no competing interests.

\section{Consent for publication}

All authors have reviewed and consented to publication of the paper.

\section{Ethics approval and consent to participate}

The study protocol was approved by the Ethic Committee of the Friendship Hospital to Urumqi and conducted in accordance with Helsinki's Declaration. All the patients gave their written information consent

\section{Publisher's Note}

Springer Nature remains neutral with regard to jurisdictional claims in published maps and institutional affiliations.

\section{Author details}

'Department of Neurology, Yangpu Hospital Tongji University School of Medicine, No. 450 Tengyue Road, Shanghai 200090, China. '²epartment of Neurology, Friendship Hospital to Urumqi, Urumai 830049, China.

\section{Received: 15 March 2017 Accepted: 22 May 2017}

\section{Published online: 17 June 2017}

\section{References}

1. Gao X, Yang H, ZhiPing T. Association studies of genetic polymorphism, environmental factors and their interaction in ischemic stroke. Neurosci Lett. 2006;398:172-7.

2. Xu G, Ma M, Liu X, Hankey GJ. Is there a stroke belt in China and why? Stroke. 2013:44:1775-83.

3. Fairbrother WG, Holste D, Burge CB, Sharp PA. Single nucleotide polymorphism-based validation of exonic splicing enhancers. PLoS Biol. 2004;2:E268

4. Szolnoki Z, Melegh B. Gene-gene and gene-environment interplay represent specific susceptibility for different types of ischaemic stroke and leukoaraiosis. Curr Med Chem. 2006;13:1627-34.

5. Chung JW, Hwang J, Lee MJ, Cha J, Bang OY. Previous Statin Use and HighResolution Magnetic Resonance Imaging Characteristics of Intracranial Atherosclerotic Plaque: The Intensive Statin Treatment in Acute Ischemic Stroke Patients With Intracranial Atherosclerosis Study. Stroke. 2016;47:1789-96

6. Linton MF, Yancey PG, Davies SS, Jerome WGJ, Linton EF, Vickers KC. The Role of Lipids and Lipoproteins in Atherosclerosis. In: De Groot L, Chrousos G, Dungan K, Feingold KR, Grossman A, Hershman JM, Koch C, Korbonits M, McLachlan R, New M, et al. editors. Endotext. South Dartmouth (MA); 2000-2005.

7. Boren J, Williams KJ. The central role of arterial retention of cholesterol-rich apolipoprotein-B-containing lipoproteins in the pathogenesis of atherosclerosis: a triumph of simplicity. Curr Opin Lipidol. 2016;27:473-83.
8. Rincon-Arevalo H, Castano D, Villa-Pulgarin J, Rojas M, Vasquez G, Correa LA, et al. Dyslipidemia-associated alterations in B cell subpopulation frequency and phenotype during experimental atherosclerosis. Atherosclerosis. 2016; 247:118-26.

9. Brown MS, Goldstein JL. A receptor-mediated pathway for cholesterol homeostasis. Science. 1986:232:34-47.

10. Teslovich TM, Musunuru K, Smith AV, Edmondson AC, Stylianou IM, Koseki $\mathrm{M}$, et al. Biological, clinical and population relevance of 95 loci for blood lipids. Nature. 2010;466:707-13.

11. Maasz A, Kisfali P, Jaromi L, Horvatovich K, Szolnoki Z, Csongei V, et al. Apolipoprotein A5 gene IVS3+G476A allelic variant confers susceptibility for development of ischemic stroke. Circ J. 2008;72:1065-70.

12. Saeed M. Editorial comment-Unraveling the pagodian architecture of stroke as a complex disorder. Stroke. 2004;35:824-5.

13. Liu M, Wu B, Wang WZ, Lee LM, Zhang SH, Kong LZ. Stroke in China: epidemiology, prevention, and management strategies. Lancet Neurol. 2007;6:456-64

14. Hu D, Sun Y. Epidemiology, risk factors for stroke, and management of atria fibrillation in China. J Am Coll Cardiol. 2008:52:865-8.

15. Hu YH, Liu JM, Zhang M, He J, Yan YZ, Ma JL, et al. Association between CETP polymorphisms and haplotypes with dyslipidemia in Xinjiang Uygur and Kazak residents. Zhonghua Xin Xue Guan Bing Za Zhi. 2016;44:671-7.

16. Quan $L, H u L$, Zhang $L$, Jiang $S$. Differences of prevalence of dyslipidemia and risk factors related to LDL-c in the patients with abnormal fasting glucose between Uygur and Han in Xinjiang. Int J Clin Exp Med. 2015;8:22403-10.

17. Li YP, Ma RL, Zhang M, Liu JM, Ding YS, Guo H, et al. Epidemic features of dyslipidemia among Uygur, Kazakh, and Han adults in Xinjiang, China in 2010. Zhonghua Yu Fang Yi Xue Za Zhi. 2013;47:949-53.

18. Yue YH, Bai XD, Zhang HJ, Li YM, Hu L, Liu LY, et al. Gene Polymorphisms Affect the Effectiveness of Atorvastatin in Treating Ischemic Stroke Patients. Cell Physiol Biochem. 2016:39:630-8.

19. Sipahi I, Swaminathan A, Natesan V, Debanne SM, Simon DI, Fang JC. Effect of antihypertensive therapy on incident stroke in cohorts with prehypertensive blood pressure levels: a meta-analysis of randomized controlled trials. Stroke. 2012:43:432-40.

20. Munshi A, Babu MS, Kaul S, Rajeshwar K, Balakrishna N, Jyothy A. Association of $L P L$ gene variant and $L D L, H D L, V L D L$ cholesterol and triglyceride levels with ischemic stroke and its subtypes. J Neurol Sci. 2012;318:51-4

21. Kotlega D, Golab-Janowska M, Masztalewicz M, Ciecwiez S, Nowacki P. Association between selected gene polymorphisms and statin metabolism, risk of ischemic stroke and cardiovascular disorders. Postepy Hig Med Dosw (Online). 2016;70:435-47.

22. Diakite B, Hamzi K, Hmimech W, Nadifi S, GMRAVC. Genetic polymorphisms of T-1131C APOA5 and ALOX5AP SG13S114 with the susceptibility of ischaemic stroke in Morocco. J Genet. 2016;95:303-9.

23. Pi Y, Zhang L, Yang Q, Li B, Guo L, Fang C, et al. Apolipoprotein A5 gene promoter region-1131T/C polymorphism is associated with risk of ischemic stroke and elevated triglyceride levels: a meta-analysis. Cerebrovasc Dis. 2012;33:558-65.

24. Lee JD, Lee TH, Kuo YW, Huang YC, Hsu HL, Lin YH, et al. Polymorphisms at the LDLR locus may be associated with ischemic cerebrovascular disease independent of lipid profile. Curr Neurovasc Res. 2012:9:200-6.

25. Yan SK, Cheng XQ, Song YH, Xiao XH, Bi N, Chen BS. Apolipoprotein A5 gene polymorphism -1131T->C: association with plasma lipids and type 2 diabetes mellitus with coronary heart disease in Chinese. Clin Chem Lab Med. 2005:43:607-12.

26. Vijayan M, Chinniah R, Ravi PM, Sivanadham R, Mosses Joseph AK, Vellaiappan NA, Krishnan Jl, Karuppiah B. MTHFR (C677T) CT genotype and CT-apoE3/3 genotypic combination predisposes the risk of ischemic stroke. Gene. 2016:591:465-70.

27. Gao F, Ihn HE, Medina MW, Krauss RM. A common polymorphism in the $L D L$ receptor gene has multiple effects on $L D L$ receptor function. Hum Mol Genet. 2013:22:1424-31.

28. Fu Y, Katsuya T, Higaki J, Asai T, Fukuda M, Takiuchi S, et al. A common mutation of low-density lipoprotein receptor gene is associated with essential hypertension among Japanese. J Hum Hypertens. 2001;15:125-30.

29. de Lange M, Snieder H, Ariens RA, Spector TD, Grant PJ. The genetics of haemostasis: a twin study. Lancet. 2001;357:101-5.

30. Zhu H, Tucker HM, Grear KE, Simpson JF, Manning AK, Cupples LA, et al. A common polymorphism decreases low-density lipoprotein receptor exon 12 
splicing efficiency and associates with increased cholesterol. Hum Mol Genet. 2007:16:1765-72.

31. Zhang J, Li X, Yang Y, Ma Y, Xie X, Xiang Y, et al. Distribution of beta3adrenergic receptors gene polymorphisms and its association with serum lipid in Han and Uighur populations in Xinjiang. Zhonghua Liu Xing Bing Xue Za Zhi. 2015:36:653-7.

32. Abulizi A, Yuan S, Ma YT, Xie X, Yang YN, Fu ZY, et al. Distributional characteristics of apolipoprotein A5 Gene c.553G > T polymorphism and association with serum triglyceride in healthy Chinese Han and Uighur people. Zhonghua Yi Xue Za Zhi. 2011;91:2837-40.

Submit your next manuscript to BioMed Central and we will help you at every step:

- We accept pre-submission inquiries

- Our selector tool helps you to find the most relevant journal

- We provide round the clock customer support

- Convenient online submission

- Thorough peer review

- Inclusion in PubMed and all major indexing services

- Maximum visibility for your research

Submit your manuscript at www.biomedcentral.com/submit
Biomed Central 